\title{
The effect of uncertainty in earthquake fault parameters on the maximum wave height from a tsunami propagation model
}

\author{
D. Burbidge ${ }^{1}$, C. Mueller ${ }^{2}$, and W. Power ${ }^{2}$ \\ ${ }^{1}$ Geoscience Australia, Canberra, Australia, now at GNS Science, Lower Hutt, New Zealand \\ ${ }^{2}$ GNS Science, Lower Hutt, New Zealand \\ Correspondence to: D. Burbidge (d.burbidge@gns.cri.nz)
}

Received: 26 March 2015 - Published in Nat. Hazards Earth Syst. Sci. Discuss.: 22 May 2015

Revised: 23 September 2015 - Accepted: 24 September 2015 - Published: 12 October 2015

\begin{abstract}
Over the last decade precomputed tsunami propagation model databases have been used extensively for both tsunami forecasting and hazard and risk assessment. However, the effect of uncertainty in the earthquake source parameters on the results of the simulated scenarios of tsunami propagation has not always been examined in great detail. Here we have undertaken a systematic study of the uncertainty in the maximum wave height of a tsunami $\left(h_{\max }\right)$ as a function of the uncertainty in the rupture parameters of the earthquake that generates it (specifically the strike, dip, rake, depth and magnitude). We have shown that even for the simple case of a tsunami propagating over flat bathymetry, the coefficient of variation $(\mathrm{CoV})$ and skewness of the distribution of $h_{\max }$ was a complex function of the choice of rupture parameter, distance and azimuth. The relationships between these parameters and $\mathrm{CoV}$ became even more complex as the bathymetry used became more realistic. This has major potential implications for both how warning centres operate in the future and how the uncertainty in parameters describing the source should be incorporated into future probabilistic tsunami hazard assessments.
\end{abstract}

\section{Introduction}

Since the 2004 Indian Ocean tsunami, there has been a major increase globally in tsunami propagation modelling for use in both tsunami warning and hazard and risk assessment. Probabilistic tsunami hazard assessments (PTHAs) have been created for the United States (Geist and Parsons, 2006; González et al., 2009), Australia (Burbidge et al., 2008, 2009), New Zealand (Power et al., 2007; Power, 2013), the Mediter- ranean (Sørensen et al., 2012; Lorito et al., 2015), the northwest Indian Ocean (Heidarzadeh and Kijko, 2011), Indonesia (Horspool et al., 2014) and the even the entire globe (Løvholt et al., 2014). At the same time, hundreds to thousands of simulated scenarios of tsunami propagation have been created to inform real-time tsunami forecasting and alerts (e.g. Greenslade et al., 2007, 2013).

One aspect that has not been studied in great detail is the sensitivity, or uncertainty, in the maximum tsunami wave height due to uncertainty in the earthquake's geometrical source parameters such as strike, dip and rake. Here we present a systematic study of this issue, starting with simple source models in a flat ocean and then moving on to three examples which use a more realistic bathymetry.

Previous studies into what affects the tsunami wavefield have mostly focused on various physical parameters such as source effects (Geist, 1999), bathymetry (Geist, 2009), tides (Weisz and Winter, 2005), dispersion of wave propagation (Glimsdal et al., 2013), Coriolis force (Shuto, 1991), effects of friction (Myers and Baptista, 2001) and land cover roughness when propagating onshore (Kaiser et al., 2011). The accuracy of tsunami simulation not only depends on the consideration of these factors in the numerical implementation, but also on the variability and uncertainties associated with them.

Dao and Tkalich (2007) reviewed the numerical effects of dispersion, Coriolis force, coordinate systems (Cartesian or spherical), bottom friction, tides and the wave equation used (Boussinesq-type versus non-linear shallow water equations). They found that astronomic tides and bottom friction have large impacts in shallow water, whereas dispersion only has a considerable effect on waves travelling over long 
distances. The particular type of numerical implementation, e.g. the choice of wave equation (linear and non-linear shallow water wave equations, Boussinesq-type or full NavierStokes equations) and their corresponding capacity to incorporate the factors mentioned above also has an influence on the accuracy of the simulation. Glimsdal et al. (2013) also found that dispersion is also a function of the dominant wavelength of the tsunami and the depth of the water at the source.

The maximum amplitude of a tsunami in the near and far field has been investigated by several authors. Geist (2009) found that the maximum tsunami amplitude in the near field was mostly due to either the direct wave or edge waves along the continental shelf. By contrast, in the far field, the maximum amplitude was most often caused by a combination of source radiation pattern, scattering, reflections and the nearshore response (edge waves, shelf modes and resonance). This work was continued in Geist (2012) who showed that far-field amplitude scaled with scalar seismic moment but with significant uncertainty in the correlation. Other studies, such as Davies et al. (2015), McCloskey et al. (2007, 2008), Løvholt et al. (2012) or Goda et al. (2014), have investigated the effect of non-uniform slip on the nearshore maximum tsunami height or on the maximum inundation height. However, these studies have generally focused on one particular location and thus on a limited range of distances and azimuths. In Geist (2002), the effect of nonuniform slip on the far field was stated to be "less than $10 \%$ " but the exact azimuth and distance at that point was not discussed.

Having a better understanding of the uncertainty in the maximum tsunami wave height has the potential to be important, not only for future tsunami hazard assessments but also tsunami forecasting and source inversions. In PTHAs it might be possible to treat the uncertainty in source parameters as an aleatory, rather than epistemic and include it in a probabilistic assessment, as discussed by Geist and Parsons (2006) or Thio et al. (2010). While in some cases this may be more computationally efficient, it may not be strictly correct according to the normal definition of those terms. Epistemic uncertainty, as defined by for example Marzocchi and Jordan (2014), is due to our lack of knowledge of the system, while aleatory uncertainty (or variability) is due to the intrinsic randomness of the system. In theory, epistemic uncertainty can be reduced by more knowledge about the system, but aleatory uncertainty cannot. So uncertainty in, say, the dip is really an epistemic uncertainty, not an aleatory one, but in some cases it may be convenient to treat it as an aleatory uncertainty anyway.

Outside of hazard assessment, another potential use would be to know how close to a warning threshold a modelled tsunami wave height from an event must be in order for the difference to be "insignificant" given the current uncertainty in the source's rupture parameters. This could then be used to inform the resulting warning given to the public. The uncertainty in source parameters could affect the reliability of assumptions made, inverting for the source using tsunami mareogram data.

For the purposes of this paper, we have focused on trying to characterise the uncertainty in the maximum offshore tsunami wave height at a particular point $\left(h_{\max }\right)$. The reason we have selected this particular model output is that this is the one most commonly used for both PTHAs and for tsunami alert threshold levels in warning systems.

The level of sensitivity in $h_{\max }$ to variations, or uncertainties, in source properties can be measured in a variety of ways. Here we have quantitatively estimated this sensitivity by calculating the coefficient of variation $(\mathrm{CoV})$ of $h_{\max }$. $\mathrm{CoV}$ was defined here to be equal to $\sigma_{\max } / \mu_{\max }$ where $\sigma_{\max }$ was the corrected sample standard deviation and $\mu_{\max }$ was the mean value of $h_{\max }$ at a particular location. Other metrics, such as $\sigma$ itself, could be used but $\mathrm{CoV}$ has the advantage of being both a dimensionless and reasonably common metric for estimating the dispersion of a distribution. We have estimated the CoV by running $N$ tsunami propagation models, each with a different value of a particular source parameter selected from a normal distribution with a standard deviation centred at the parameter's mean. The normal distribution was chosen mainly for convenience as it is a simple, common example of an uncertainty distribution. The actual uncertainty distribution for some parameters could in fact be quite complex. For example, the uncertainty in the strike may vary with magnitude. However, in most cases, the correct distribution is not known and the normal distribution has the advantage of being simple. Given these assumptions, $\sigma_{\max }$ at a given point is then

$\sigma_{\max }(x, y)=\sqrt{\frac{1}{N-1} \sum_{i=1}^{N}\left(h_{\max }^{i}(x, y)-\mu_{\max }(x, y)\right)^{2}}$,

where $h_{\max }^{i}(x, y)$ was the maximum tsunami wave height at a particular location for the $i$ th model run.

To the authors' knowledge, previous studies into tsunami sensitivity or uncertainty with respect to variations in the source parameters have typically been very location- and event-specific and/or have only considered a few parameters with a handful of models (i.e. $N$ in the equation above was small). For example, Titov et al. (1999) and Gica et al. (2007) studied the effect of various combinations of dip, strike, rupture dimensions, hypocentre, slip displacement and rake angle on offshore tsunami maximum wave heights near Hawaii from earthquakes from the Aleutian Islands, Chile and Japan. While this was a comprehensive list of parameters, the limited number of sources and target sites make it difficult to know to what degree the results of that study can be applied to other areas. For the location and events that they did study, they found that the tsunami wave height at distance is mostly affected by changes in fault dimensions, strike angle and slip displacement but not as much by rake, dip, epicentre location and focal depth. Thus their conclusion was that the earth- 
quake could not be entirely treated as a point source in the far field.

Okal and Synolakis (2008) also performed a few tests on the effect of shifting the epicentre and rake on maximum tsunami wave heights predicted from their numerical model. Again, this was only for a few examples and therefore cannot be used to calculate the CoV. However, they did conclude from their study that the far-field pattern was robust to these variations. Okal and Synolakis (2004) also examined the effect of varying a range of rupture parameters on the maximum run-up from nearshore events. However, they did not examine the $\mathrm{CoV}$ on the maximum run-up nor the effect on the maximum offshore wave height from more distant events. In addition, Løvholt et al. (2012) examined the effect of changing the dip and depth on the CoV from a set of heterogeneous slip events using a plane wave tsunami model with idealised bathymetry. They found that the CoV of the maximum run-up from varying the slip decreased when the depth of the fault was increased but was unchanged when the dip was varied. However, they did not specifically look at the CoV from varying the bulk rupture parameters (eg strike, dip or depth) nor did they examine the effect of changing the distance to the rupture or the azimuth. Xing et al. (2015) examined the effect of strike, rake, dip and magnitude on the maximum tsunami wave height at locations off the eastern coast of Australia for two tsunami sources, one on the New Hebrides Trench and one on the Puysegur Trench. They found that $h_{\max }$ was changed when any of these parameters were varied. However, these authors only studied five cases per parameter, and again the study was specific to a particular set of locations and sources. Finally, Goda et al. (2015) has recently published a study looking at the variation in inundation footprints in the Tohoku region of Japan from different fault geometries (top edge depth, strike and dip) and slip distributions. They found that the sensitivity to these parameters was highly dependent on tsunami source characteristics and site location and therefore complex and highly non-linear.

Here we have looked at how the $\mathrm{CoV}$ changes for a range of azimuths and distances for a given uncertainty in a particular rupture parameter using one particular tsunami propagation model, EasyWave (Babeyko, 2012). The rupture parameters chosen for this study were strike, dip, rake, magnitude and depth. The slip on all the models shown was uniform and the rupture dimensions were based on Abe (1975). We have done this in order to answer the following simple questions.

- Does the CoV vary with distance, azimuth or magnitude and how is it affected by bathymetry?

- Is $h_{\max }$ normally distributed? If not, is the shape of the distribution also a function of distance, azimuth, magnitude or bathymetry?

If the $\mathrm{CoV}$ does not vary significantly due to these factors and $h_{\max }$ was normally distributed, this could significantly simplify both PTHAs and tsunami forecasting. The main pur- pose of this paper is to see the extent to which we can assume that this is true for this particular set of examples.

\section{Method}

The method used here for assessing the uncertainty in $h_{\max }$ was conceptually simple, if computationally intensive. It consisted of the following steps.

1. Choose a bathymetry.

2. Select a standard (or reference) set of rupture parameters.

3. Choose a random number from a normal distribution with a width given by the standard deviation in the parameter to be studied $\left(\sigma_{\text {strike }}, \sigma_{\text {dip }}, \sigma_{\text {rake }}\right.$ or $\sigma_{\text {depth }}$ depending on the parameter).

4. Run the tsunami propagation model with this parameter and then save the maximum wave height at all points in the model's domain.

5. Repeat steps 3 and 4 for $N$ iterations, each with a different, randomly generated, value of the parameter to be studied. Save the maximum wave heights at all points in the model for each iteration.

6. Use these models to calculate $\mu_{\max }$ across the model domain.

7. Use Eq. (1) to calculate $\sigma_{\max }$ for all points in the model domain.

8. Calculate the ratio of $\sigma_{\max }$ and $\mu_{\max }$ to calculate the $\mathrm{CoV}$ at every point in the domain.

9. Map the resulting $\mathrm{CoV}$ values.

In addition to calculating the $\mathrm{CoV}$, we have also binned the $N$ models in order to examine the shape of the resulting distribution.

Finally, we have also mapped the sample skewness in order to provide a more quantitative measure of the shape of the distribution of $h_{\max }$ across the model's domain. The sample skewness, $S$, was given by (Mantalos, 2010)

$S=\frac{\frac{1}{N} \sum_{i=1}^{N}\left(h_{\max }^{i}-\mu_{\max }\right)^{3}}{\left(\frac{1}{N} \sum_{i=1}^{N}\left(h_{\max }^{i}-\mu_{\max }\right)^{2}\right)^{3 / 2}}$.

When $S>0$, the distribution is usually skewed to the right, i.e. it has a large (or heavy) tail above the mean. Log-normal distributions are an example of this type of distribution. When $S<0$, the distribution is skewed to the left and the heavy tail is below the mean. If $S=0$ then the distribution 
is evenly distributed around the mean (as it would be for the normal or uniform distribution for example). Maps of $S$ allowed us to see whether the shape of distribution of $h_{\max }$ changed with azimuth or distance.

For the studies shown here, we have set $N=100$. To test that this was adequate, we ran one set of runs with $N=50$ and found that this changed the maximum $\mathrm{CoV}$ in a test model by $11 \%$. However, when we ran one set of models with $N=200$, we found that this changed the maximum $\mathrm{CoV}$ observed in the model by less than $1 \%$. Therefore $N=100$ was chosen as a reasonable balance between accuracy in the maps and computational speed.

\subsection{Bathymetry}

For this study we used three increasingly complex bathymetry data sets. The first was a $80^{\circ} \times 80^{\circ}$ bathymetry model with a constant depth of $3678 \mathrm{~m}$ (the average depth of the ocean, Charette and Smith, 2010). The boundaries of the model go from -140 to $140^{\circ}$ in longitude and from -40 to $40^{\circ}$ in latitude. The second bathymetric data set was an $80^{\circ}$ latitude by $42^{\circ}$ longitude bathymetry model with a constant depth of $3678 \mathrm{~m}$ up until a step up in the elevation to $100 \mathrm{~m}$ a.m.s.l. (above mean sea level) near the eastern edge of the model domain. This model went from 140 to $181.25^{\circ}$ in longitude but had the same range in latitude. The step at effectively acts as a reflecting wall. Both models were calculated on a 4 arcmin grid. The first bathymetry can be viewed as a simplified version of the bathymetry near an oceanic subduction zone and the second for a (highly) simplified continental subduction zone. Having uniform bathymetry removes bathymetry variations from the problem and allows us to understand the patterns in $\mathrm{CoV}$ better. The stepped model could be made more like an actual continental margin by (for example) including a sloped ramp up to $100 \mathrm{~m}$. However, the main aim of this bathymetry is just to demonstrate the effect of a basic process, in this case a simple reflection, rather than be a demonstration of the effect of a continental margin on CoV or skewness.

Some models were also run with both a 2 arcmin and a 8 arcmin grid and in both cases there was only a small change in the maximum $\mathrm{CoV}$ observed in the model (less than $5 \%$ ). However, there were some minor changes in the pattern. Therefore some of the details in the maps shown later could be influenced by the numerical resolution of the grid. This could be due to the different levels of numerical dispersion in the models with different grid resolutions or because some of the details of the initial deformation pattern and subsequent waves were missed for the coarser resolutions. However, the overall pattern appeared to be independent of the model resolution.

The final bathymetry model used consisted of two subsections of ETOPO2 global elevation model (NOAA, 2006). Both were calculated on a 2 arcmin grid. ETOPO2 is one of the standard bathymetry models commonly used for tsunami propagation calculations. These models illustrated the effect of realistic bathymetry on the $\mathrm{CoV}$ and $S$ maps.

\subsection{Reference fault parameters}

The uniform and stepped bathymetry tsunami runs used a uniform slip model with a set of "standard" values. The standard values were

$-\operatorname{dip}=20^{\circ}$;

- strike $=0^{\circ}$;

- rake $=90^{\circ}$;

- depth to the top edge of the rupture $=10 \mathrm{~km}$.

When a parameter was varied randomly the standard value listed above was the random distribution's mean.

The standard value of the dip was chosen to be $20^{\circ}$ as this is a typical value for the average dip of the seismogenic part of a subduction zone (e.g. the average dip of the interface in Slab 1.0 of Hayes et al. (2012) varies from 8 to $30^{\circ}$ depending on the zone). Since we are mainly interested in tsunamigenic earthquakes the rake was set to be pure thrust. Since the rake was pure thrust, variations around that value add a strike-slip component to the motion and thus will generally reduce the amplitude of the tsunami. The depth of the top edge was kept quite shallow $(10 \mathrm{~km})$ as a typical "worst" case scenario. As a reviewer pointed out, when the depth is this shallow and the slip is uniform the initial sea surface displacement will have a distinct (and probably artificial) peak. The strike was chosen to propagate the tsunami along the equator and minimise any distortions simply due to the map projection. It also made the north and south parts of the domain symmetric which is a check that the sampling is adequate.

The sea floor deformation created by these sources was calculated on $10 \times 10 \mathrm{~km}$ patches (i.e. sub-faults) using the Okada equations as implemented in EasyWave, and then summed. Given that all the models considered in this paper had uniform slip, a single large source could also have been used. Patches were used instead since the original intention was to compare the CoVs and $h_{\max }$ distributions from uniform and non-uniform slip models using the same sized set of sub-faults. This turned out to not be required to demonstrate complexity in the uncertainty patterns. One aspect of using sub-faults is that there may be small edge effects in the initial sea surface displacement when compared to that which would have been produced by a single, larger fault.

The fault's centroid was positioned at $180^{\circ} \mathrm{W}, 0^{\circ} \mathrm{N}$ and dipped to the east. The scaling relationship used to estimate the rupture dimensions and slip for a particular magnitude were based on the scaling relations of Abe (1975) rounded to the nearest $10 \mathrm{~km}$. These relations hold for magnitudes up to that at which the rupture width extends for the full width of the fault plane (to the brittle ductile boundary where faultlocking no longer occurs). For the purposes of this study, 
the maximum width was assumed to be $150 \mathrm{~km}$. Above this magnitude it was assumed that the displacement continues to scale proportionately with the fault length; this is known as the L-model (Scholz, 1982; Hanks and Bakun, 2002). Although other, more recent, scaling relations could have been used, this particular set of scaling relations had the advantage of already being implemented in the computational framework (see Sect. 2.3) and the effect of different scaling relations on $h_{\max }$ and $\mathrm{CoV}$ was not intended to be the main focus of this study.

For the models which were run using the ETOPO2 bathymetry, the epicentre and mean strike used were those of the 2011 Kermadec earthquake, 2007 Solomon Islands earthquake or the 2006 Java earthquake. The strike of these models was set to be equal to that for one of the nodal planes for these events calculated by the USGS. Note that only the epicentre and strike were based on these events; the dip and rake were kept the same as the flat and stepped bathymetry examples in order to aid comparison. These three locations were chosen as they are good examples of subduction zones from different tectonic environments and thus bathymetries. The Kermadec zone is on a fairly typical oceanic subduction zone, the Solomon Islands zone is an example of a zone with complex bathymetry in the source region (i.e. multiple small islands) and Java is a typical example of a continental subduction zone.

\subsection{Numerical models and scripts}

The tsunami propagation model used here was EasyWave (Babeyko, 2012). The main reason this particular model was chosen was that it has been optimised for computational speed and is open-source (http://trac.gfz-potsdam.de/ easywave). The time step for all the models shown here was the one calculated automatically by EasyWave. For the purpose of the uncertainty calculations, the Coriolis effect was not included.

A robust and efficient framework was required to manage the large amount of data and the simulated scenarios this method produced. A Python-based object oriented application programming interface (API) was developed that augments and drives the EasyWave tsunami simulation program. The API allowed us to automate this parameter study using EasyWave as the tsunami simulation kernel. All the source models investigated in this study were created and managed with this API. The API also managed simulation on GNS Science's cluster used for the computations, i.e. it farmed simulation scenarios out to cluster and collected data after simulation completion.

All the subsequent post-processing, including the map generation, was calculated by a set of post-processing GMT scripts (Wessel et al., 2013). The output grids from EasyWave and for the statistics were a mix of Golden Software ${ }^{(}$ format files produced by EasyWave and NetCDF format files created by GMT.

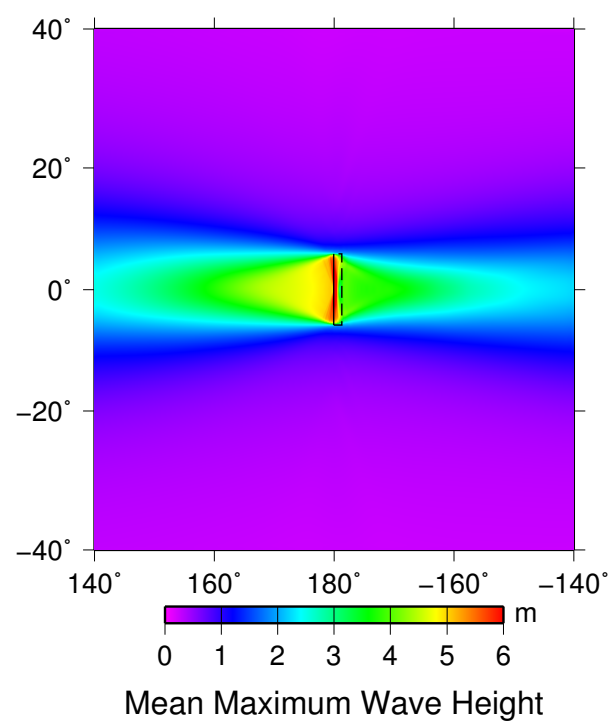

Figure 1. The mean of the maximum tsunami wave height ( $\mu_{\max }$ in metres) for a $M_{\mathrm{W}}=9.5$ event with a $\sigma_{\text {strike }}=10^{\circ}$. The bathymetry is uniform and completely flat. The earthquake's rupture has a $20^{\circ}$ dip to the right, its mean strike is north-south (i.e. $0^{\circ}$ ), the depth to the top edge is $10 \mathrm{~km}$ and it is centred at $180^{\circ} \mathrm{W}, 0^{\circ} \mathrm{S}$. The slip along the rupture plane is uniform and has a $90^{\circ}$ rake (i.e. it is a pure thrust earthquake). The black box on the figure shows the surface projection of the mean rupture plane. The solid line on the left is the top edge of the plane and the dashed line on the right is the bottom edge.

\section{Results}

\subsection{Uniform, flat bathymetry}

\subsubsection{Strike}

Figure 1 shows the mean maximum wave height $\left(h_{\max }\right)$ over 100 uniform slip models with $\sigma_{\text {strike }}$ of $10^{\circ}$ and a magnitude of $M_{\mathrm{w}}=9.5$. This level of uncertainty would be typical for a well-constrained earthquake focal mechanism. The total rotational uncertainty (strike and dip) for a focal mechanism is typically between 5 and $20^{\circ}$ (Kagan, 2003). The other parameters are at their standard values (see Sect. 2.2). The bathymetry was flat with a uniform depth. As one might expect, the tsunami propagated as two "beams"; one going to the east and one to the west of the earthquake rupture's initial location. The effect of averaging over 100 models with varying strike was that these beams become more "smeared" at their edges than they would be if only one model was simulated.

Figure 2a-c shows maps of the $\mathrm{CoV}$ of $h_{\max }$ from three sets of earthquakes with magnitudes $M_{\mathrm{w}}=7.5,8.5$ and 9.5, respectively. The sets of earthquakes varied in the strike by $10^{\circ}$ but were otherwise the same. As can be seen, the largest values of $\mathrm{CoV}$ were on each side of the two tsunami beams (Fig. 1). The CoV was higher and more focused on the foot- 

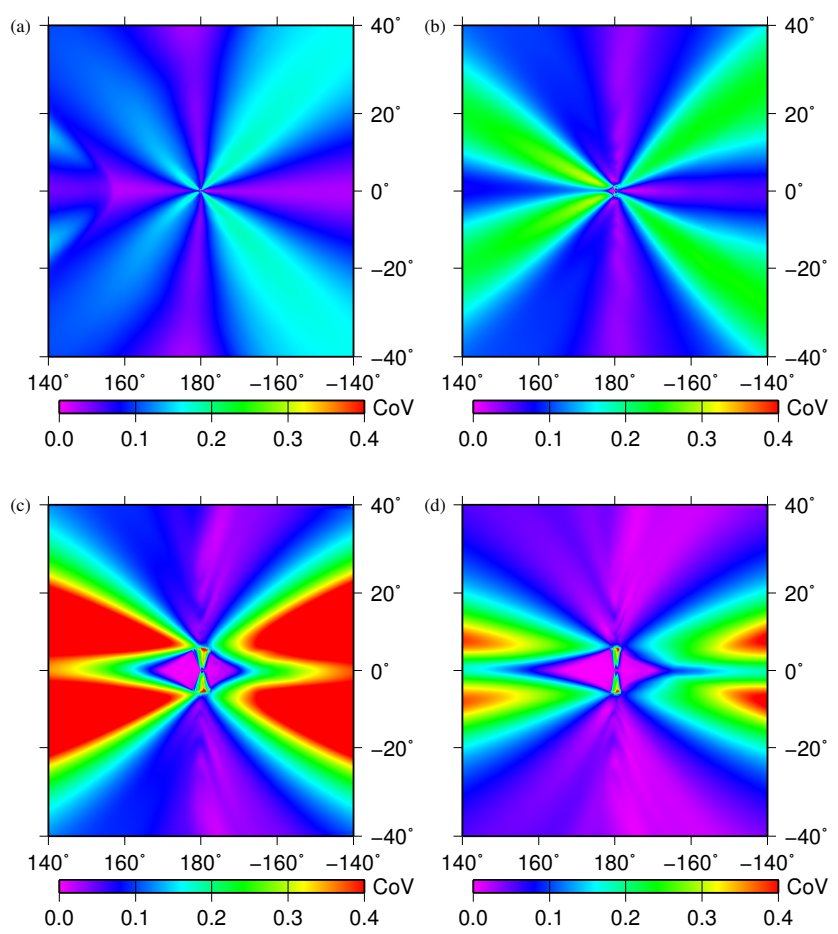

Figure 2. The effect of $\sigma_{\text {strike }}$ on the coefficient of variation $(\mathrm{CoV})$ of $h_{\max }$. (a) shows the CoV map from a set of 100 tsunami generated by $M_{\mathrm{W}}=7.5$ earthquakes which vary only in strike. (b) and (c) show the effect on $\mathrm{CoV}$ when the magnitude of these events are increased to $M_{\mathrm{W}}=8.5$ and $M_{\mathrm{W}}=9.5$. For (a)-(c) $\sigma_{\text {strike }}=10^{\circ}$. The bathymetry and other parameters are the same as in Fig. 1. Note that values above 0.4 are all shaded the same colour. 0.4 was chosen to be the maximum for these figures in order to be consistent with later figures. (d) shows the $\mathrm{CoV}$ map from a set of $M_{\mathrm{W}}=9.5$ events with a $\sigma_{\text {strike }}=5^{\circ}$.

wall (left) beam than for the hanging wall (right) beam for $M_{\mathrm{w}}=7.5$ (Fig. 2a) but not for the higher magnitudes. The variance was always at a minimum along strike (i.e. due north and south along the $180^{\circ} \mathrm{W}$ line of longitude). The range of $\mathrm{CoV}$ values went from 0.7 to 0.001 for $M_{\mathrm{w}}=9.5$. For $M_{\mathrm{w}}=7.5$ it ranged from 0.3 to 0.001 but the bulk of the region was well below 0.2. For $M_{\mathrm{w}}=9.5$ the most common CoVs across the model domain were between 0.05 and 0.1 but many of the points were between 0.5 and 0.7 (histogram not shown, but this can be seen from the range of colour values in Fig. 2c). Overall, the pattern was symmetric between the northern and southern halves of the model domain. However, on close inspection some minor asymmetries were seen between the northern half of the model and the southern half, particularly due north and south of the earthquake's epicentre. These are likely to be due to a combination of the finite number of samples and small numerical errors (e.g. roundoff).

Just from this figure we can see that uncertainty in the strike makes the biggest difference (in terms of CoV) just off the main direction of the tsunami propagation. This means
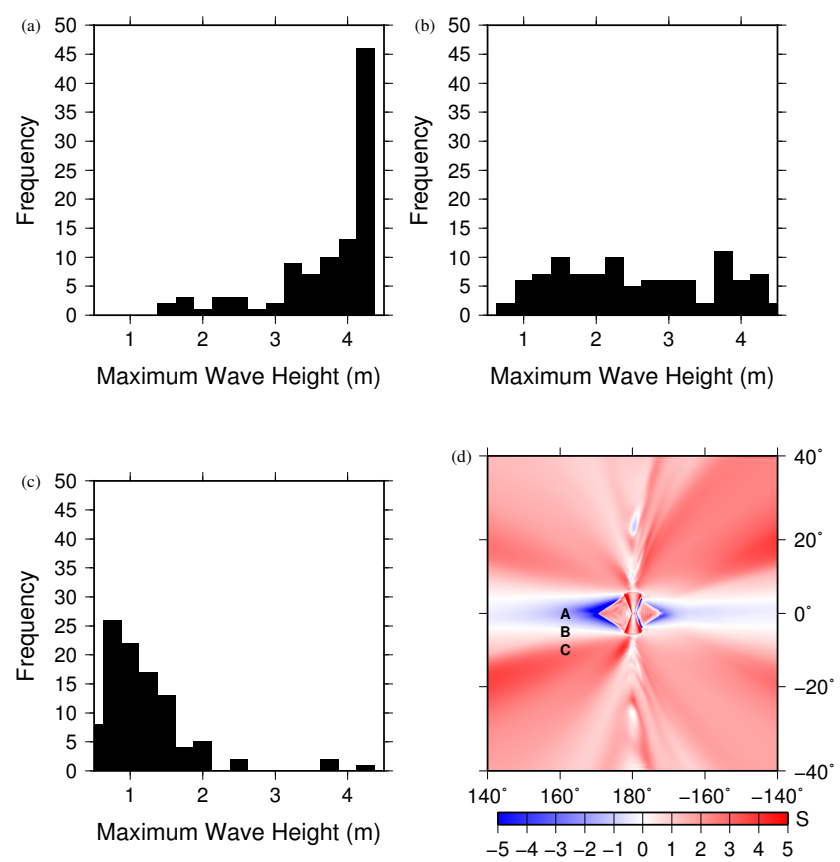

Figure 3. Example histograms for three locations surrounding a $M_{\mathrm{W}}=9.5$ event with a $\sigma_{\text {strike }}=10^{\circ}$. (a) is at $160^{\circ} \mathrm{E}, 0^{\circ}$ and is directly in the mean path of the beam. This is an example of a location where the distribution has a strong negative skew. (b) is an example at the edge of the beam $\left(160^{\circ} \mathrm{E}, 5^{\circ} \mathrm{S}\right)$. It is not skewed, but nor is it normally or log-normally distributed. (c) is at $160^{\circ} \mathrm{E}, 10^{\circ} \mathrm{S}$ and is thus just off the beam. This is an example of a location where the distribution of maximum wave heights has a strong positive skew. (d) shows the location of the histograms in (a)-(c) relative to the rupture. The background image shows the skewness (see Eq. 2) of the maximum tsunami wave height distribution across the domain.

an error in the strike in (for example) a tsunami forecast will make the largest difference to the amplitude in that location. Also, if one were to invert for the tsunami source, an observation in these areas is likely to be much more helpful in constraining the strike rather than a point due north or south of the source.

Figure $2 \mathrm{~d}$ shows the $\mathrm{CoV}$ map when $\sigma_{\text {strike }}$ is reduced to $5^{\circ}$ for a magnitude of $M_{\mathrm{w}}=9.5$. In this case, reducing $\sigma_{\text {strike }}$ did not change the pattern very much but reduced the amplitude and concentrated the larger $\mathrm{CoV}$ values into a smaller area. The maximum value of $\mathrm{CoV}$ reduced to 0.5 (down from 0.7 ). Also, the maximum effects of strike uncertainty occurred further from the source.

Figure $3 \mathrm{a}-\mathrm{c}$ show the histogram of the maximum wave heights at locations A-C on Fig. $3 \mathrm{~d}$ for a $M_{\mathrm{w}}=9.5$ event. As can be seen, the distribution of maximum wave heights was far from being normally distributed at the locations shown. For location A the distribution had a strong negative skew, while for $\mathrm{C}$ it had a strong positive skew. At $\mathrm{B}$ the distribution was not significantly skewed, but was close to uniform. This was despite $\sigma_{\text {strike }}$ having a Gaussian distribution. Figure $3 \mathrm{~d}$ 

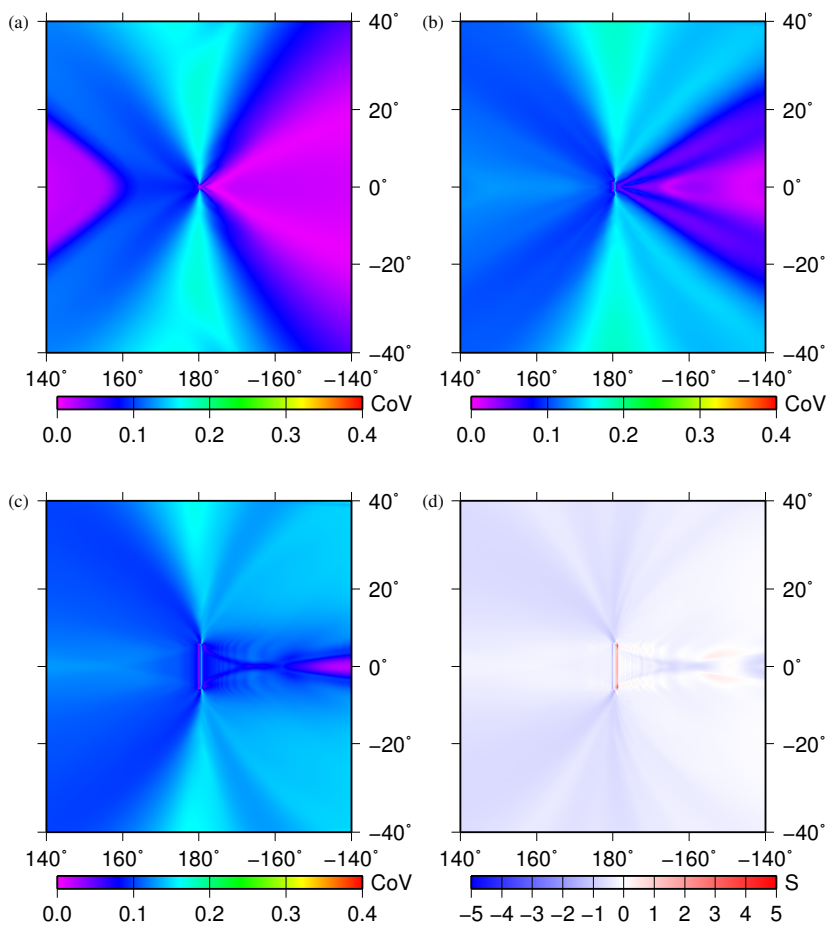

Figure 4. The effect of $\sigma_{\text {dip }}$ on the $\mathrm{CoV}$ and skewness of $h_{\max }$. The magnitude of the earthquakes for each set were (a) $M_{\mathrm{W}}=7.5$, (b) $M_{\mathrm{W}}=8.5$ or (c) $M_{\mathrm{W}}=9.5 . \sigma_{\mathrm{dip}}=5^{\circ}$ for all the sets shown here. The mean dip is $20^{\circ}$. The strike is fixed to be due north-south. The bathymetry and other parameters are otherwise the same as in Fig. 2 and are held constant for all 100 iterations. (d) The skewness of the distribution of the maximum tsunami wave heights for a $M_{\mathrm{W}}=9.5$ and $\sigma_{\text {dip }}=5^{\circ}$.

also shows the skewness values across the whole region more generally. The $h_{\max }$ distributions were generally positively skewed, except for points in the beam close to the source where they were negatively skewed.

\subsubsection{Dip}

Figure $4 \mathrm{a}-\mathrm{c}$ show the $\mathrm{CoV}$ maps when $\sigma_{\text {dip }}$ is $5^{\circ}$ for a $M_{\mathrm{w}}=7.5,8.5$ and 9.5 events, respectively. Different plate models typically differ by between 1 to $10^{\circ}$ in their estimates of the average dip of an interface (e.g. see Table 1 in Hayes et al., 2012), so $5^{\circ}$ was chosen as a reasonable estimate of the typical uncertainty in dip. The other parameters were held at their reference values.

Unlike the previous example, the maximum $\mathrm{CoV}$ was along strike (i.e. to the north and south of the epicentre) rather than to each side of the tsunami beam. So unlike the strike, an error in the dip has a bigger effect along strike than just off the main direction of propagation. For the $M_{\mathrm{w}}=7.5$ example it was also higher in the hanging wall direction (to the right of the figure) rather than the footwall direction. This difference became less strong (more concentrated into a smaller region) as the magnitude increased. The $\mathrm{CoV}$ ranged
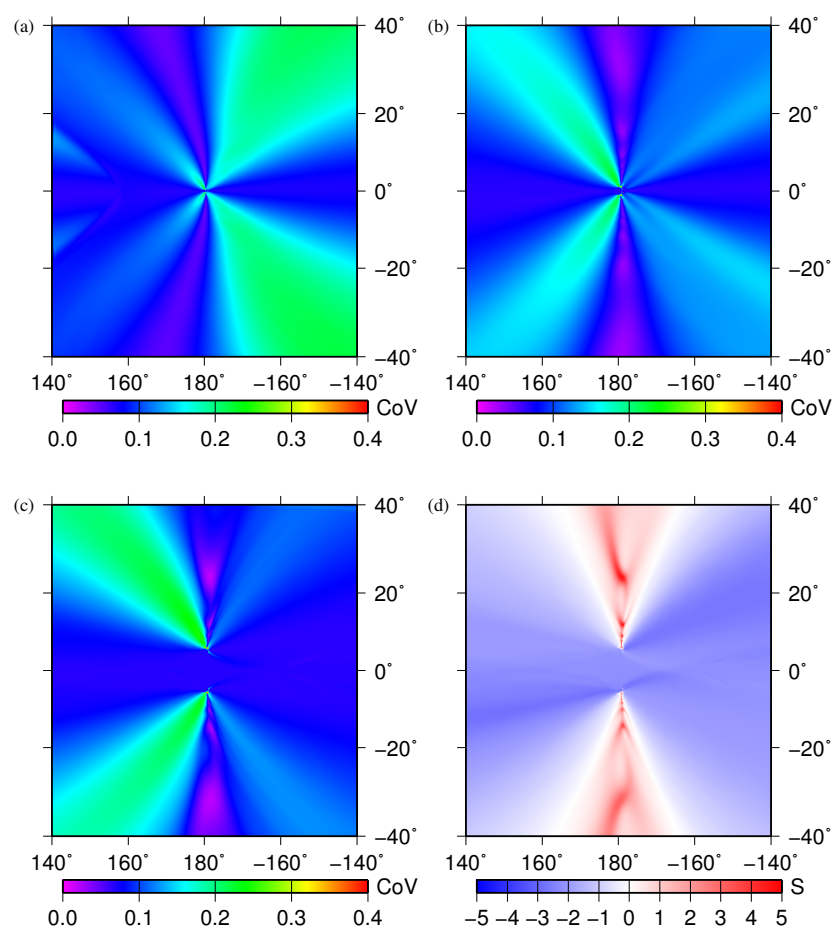

Figure 5. The effect of $\sigma_{\text {rake }}$ on the $\mathrm{CoV}$ and skewness of $h_{\max }$. The magnitude of the earthquakes for each set were (a) $M_{\mathrm{W}}=7.5$, (b) $M_{\mathrm{W}}=8.5$ or (c) $M_{\mathrm{W}}=9.5 . \sigma_{\text {rake }}=20^{\circ}$ for all the sets shown here. The mean rake is $90^{\circ}$. The bathymetry and other parameters are otherwise the same as in the previous examples. (d) The skewness of the distribution of the maximum tsunami wave heights for a $M_{\mathrm{W}}=9.5$ and $\sigma_{\text {rake }}=20^{\circ}$.

from 0.4 to 0.01 for $M_{\mathrm{w}}=9.5$ and from 0.2 to 0.002 for $M_{\mathrm{W}}=7.5$.

Figure $4 \mathrm{~d}$ shows the skew pattern for the $M_{\mathrm{w}}=9.5$ case. In this case the distributions were not as skewed as they were in the previous example. The skew was generally small and negative except immediately above the rupture where it was either strongly positive or negative.

\subsubsection{Rake}

Figure 5a-c show the CoV maps when $\sigma_{\text {rake }}$ is set equal to $20^{\circ}$ for a $M_{\mathrm{w}}=7.5,8.5$ and 9.5 event, respectively. Again, this is typical uncertainty in a well-constrained focal mechanism (e.g. see Shaw and Jackson, 2010). For the $M_{\mathrm{w}}=7.5$ case the regions of maximum $\mathrm{CoV}$ were on the hanging wall of the fault and on the footwall side for $M_{\mathrm{w}}=8.5$ and 9.5. Unlike the previous two examples, the range of the $\mathrm{CoV}$ for the $M_{\mathrm{w}}=9.5$ and $M_{\mathrm{w}}=7.5$ events was essentially identical. It ranged from 0.3 to 0.005 for $M_{\mathrm{w}}=9.5$ and from 0.3 to 0.04 for $M_{\mathrm{w}}=7.5$.

The skewness for the $M_{\mathrm{w}}=9.5$ set of events is shown in Fig. $5 \mathrm{~d}$. To the north and south of the rupture the distributions had a positive or zero skew. Everywhere else the distributions were negatively skewed. 

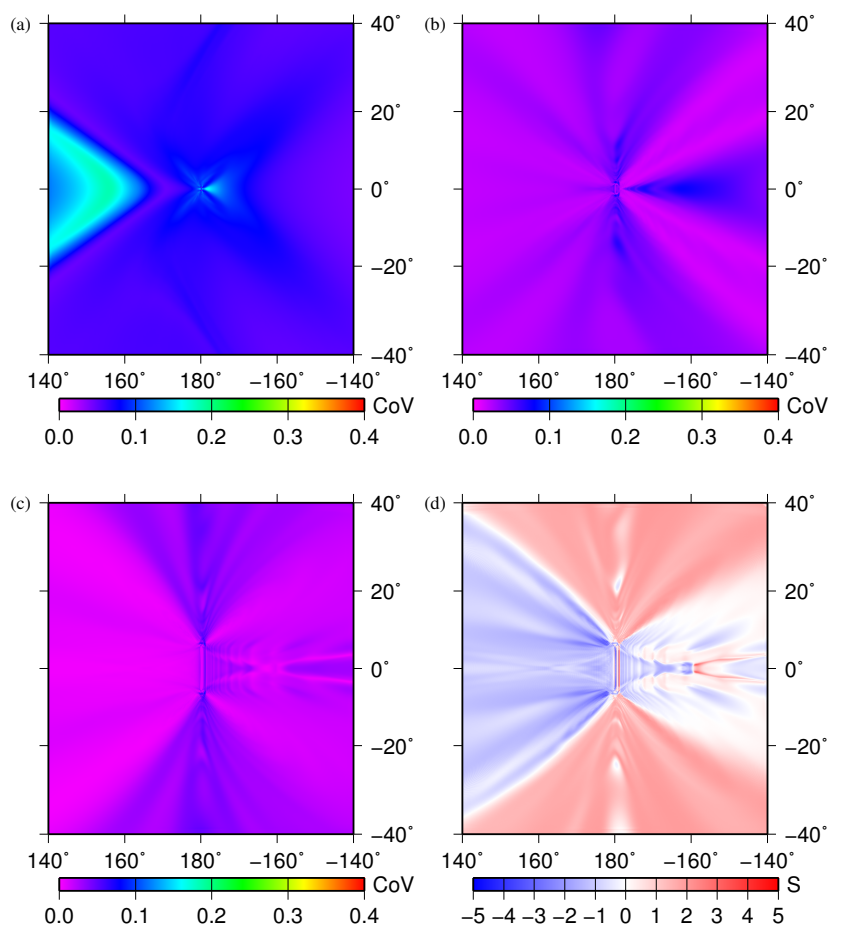

Figure 6. The effect of $\sigma_{\text {depth }}$ (depth to the top edge of the rupture) on the $\mathrm{CoV}$ and skewness of $h_{\max }$. The magnitude of the earthquakes for each set were (a) $M_{\mathrm{W}}=7.5$, (b) $M_{\mathrm{W}}=8.5$ or (c) $M_{\mathrm{W}}=9.5 . \sigma_{\mathrm{depth}}=2.5 \mathrm{~km}$ for all the figures shown here. The mean depth to the top edge was $10 \mathrm{~km}$. The bathymetry and other parameters are otherwise the same as in the previous examples. (d) The skewness of the distribution of the maximum tsunami wave heights for a $M_{\mathrm{W}}=9.5$ and a $\sigma_{\text {depth }}=2.5 \mathrm{~km}$.

\subsection{Depth}

Figure 6a-c show the $\mathrm{CoV}$ maps when the depth to the top edge of the fault was varied by a $\sigma_{\text {depth }}$ of $2.5 \mathrm{~km}$ for sets of $M_{\mathrm{w}}=7.5,8.5$ and 9.5 events. Depths above $0 \mathrm{~km}$ were rejected to prevent "air quakes". This uncertainty is fairly low for a typical earthquake, but was chosen to ensure that the distribution in depth is still approximately Gaussian after removing the "air quakes".

These CoV maps had higher values on the hanging wall side than the footwall side for the $M_{\mathrm{w}}=7.5$ case (Fig. 6a). The $\mathrm{CoV}$ was also generally higher for $M_{\mathrm{w}}=7.5$ than for the other magnitudes. However, overall the $\mathrm{CoV}$ was much lower than for strike variations. The range of $\mathrm{CoV}$ went from 0.2 to 0.002 for the $M_{\mathrm{w}}=9.5$ set of events and from 0.2 to 0.03 for $M_{\mathrm{w}}=7.5$ set. However, the area covered with a high $\mathrm{CoV}$ was much larger for the $M_{\mathrm{w}}=7.5$ case than it was for the $M_{\mathrm{W}}=9.5$ case.

The skewness was negative on the footwall (left) side, positive to the north and south of the rupture and mostly near zero on the hanging wall side for the $M_{\mathrm{w}}=9.5$ case (Fig. 6d).
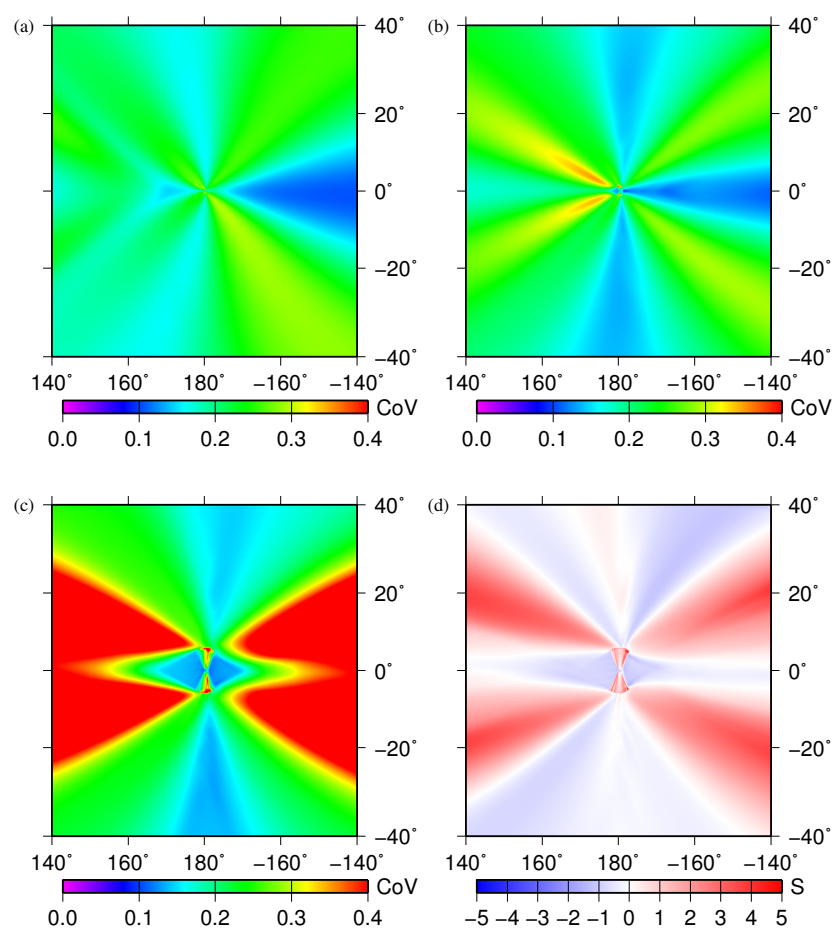

Figure 7. The effect of varying multiple fault parameters on the $\mathrm{CoV}$ and skewness. The magnitude of the earthquakes for each set were again (a) $M_{\mathrm{W}}=7.5$, (b) $M_{\mathrm{W}}=8.5$ or (c) $M_{\mathrm{W}}=9.5$. $\sigma_{\text {strike }}=10^{\circ}, \sigma_{\text {dip }}=5^{\circ}, \quad \sigma_{\text {rake }}=20^{\circ}$ and $\sigma_{\text {depth }}=2.5 \mathrm{~km}$. The bathymetry and other parameters are otherwise the same as in the previous examples. (d) The skewness of the distribution of the maximum tsunami wave heights for a $M_{\mathrm{W}}=9.5$ and these $\sigma$ values.

\section{Multiple parameters}

The final example for the uniform bathymetry case we show here is one where all the parameters are allowed to vary around their reference values. In the example shown in Fig. 7, $\sigma_{\text {strike }}=10^{\circ}, \sigma_{\text {dip }}=5^{\circ}, \sigma_{\text {rake }}=20^{\circ}$ and $\sigma_{\text {depth }}=2.5 \mathrm{~km}$. The magnitudes varied between $M_{\mathrm{w}}=7.5,8.5$ and 9.5. As one might expect this pattern was a combination of all the previous patterns; in this particular case it is dominated by the strike pattern, particularly for the higher magnitudes. The CoV ranged for $M_{\mathrm{w}}=9.5$ from 0.6 to 0.1 and for $M_{\mathrm{w}}=7.5$ from 0.4 to 0.1 . For $M_{\mathrm{w}}=9.5$, skewness varied from strongly positive to weakly negative depending on the azimuth (Fig. 7d).

\subsection{Stepped bathymetry}

Figure 8a shows what happens to a $\mathrm{CoV}$ map if a reflecting barrier is placed due east of the fault. In this particular example, we show the effect on the $\mathrm{CoV}$ for a $M_{\mathrm{w}}=9.5$ uniform slip rupture with $\sigma_{\text {strike }}=10^{\circ}$. As described in Sect. 2.1 the bathymetry increased east of $182.5^{\circ}$ to $100 \mathrm{~m}$ a.s.l. (above sea level). Everywhere else it was the same as in the previous examples. As can be seen in this example, the beam and the 


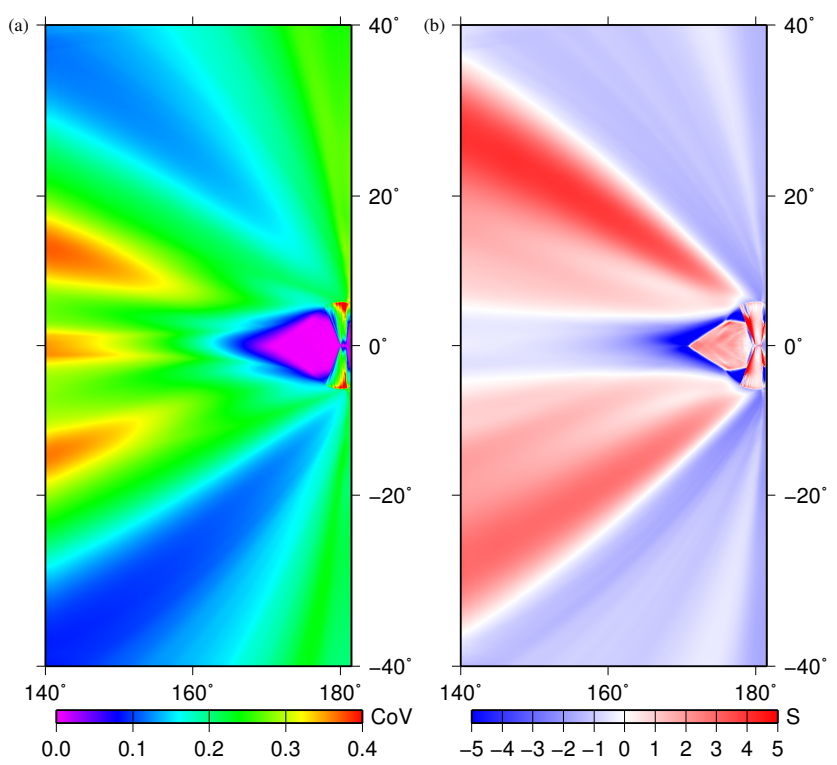

Figure 8. The effect of having a step in the bathymetry on the CoV and skewness of $h_{\max }$. (a) shows the CoV from a set of $M_{\mathrm{W}}=9.5$ events with a $\sigma_{\text {strike }}=10^{\circ}$. The elevation has a step at $182.5^{\circ}$ where it suddenly increases to $100 \mathrm{~m}$ a.m.s.l. The other parameters are otherwise the same as in Fig. 2b. (b) The effect of the step on the skewness of the distribution of the maximum tsunami wave heights (cf. Fig. 3b).

regions just to each side of the beam had the highest $\mathrm{CoV}$. The $\mathrm{CoV}$ also increased as one moved further away from the source. The range of the $\mathrm{CoV}$ for this example was from 0.5 to 0.001 just to the west of the epicentre.

Figure $8 \mathrm{~b}$ shows the effect of this on the skewness field (cf. Fig. 3b). The areas to both sides of the beam were strongly positively skewed; those elsewhere were negatively skewed. The pattern also changed immediately above and to the west of the fault, where it was mostly positively skewed but with some areas which had a strong negative skewness.

\subsection{Realistic bathymetry}

The previous examples all used flat or stepped bathymetric models. While this is very useful for determining basic patterns, in real cases, the bathymetry is highly non-uniform. Here we repeat some of the above experiments for hypothetical earthquakes on the Kermadec, Solomon Islands and Java subduction zones. The bathymetry used for these three examples is shown in Fig. 9.

\subsubsection{Kermadec event}

Figure $10 \mathrm{a}-\mathrm{c}$ shows the $\mathrm{CoV}$ maps for (a) $\sigma_{\text {strike }}$ of $10^{\circ}$, (b) $\sigma_{\text {dip }}$ of $5^{\circ}$ and (c) all the rupture parameters being allowed to vary. The epicentre of the event was at $183.762^{\circ} \mathrm{E}$, $28.993^{\circ} \mathrm{S}$. The mean strike was $205^{\circ}$. The other parameters were the same as those list in Sect. 2.2. The magnitude is

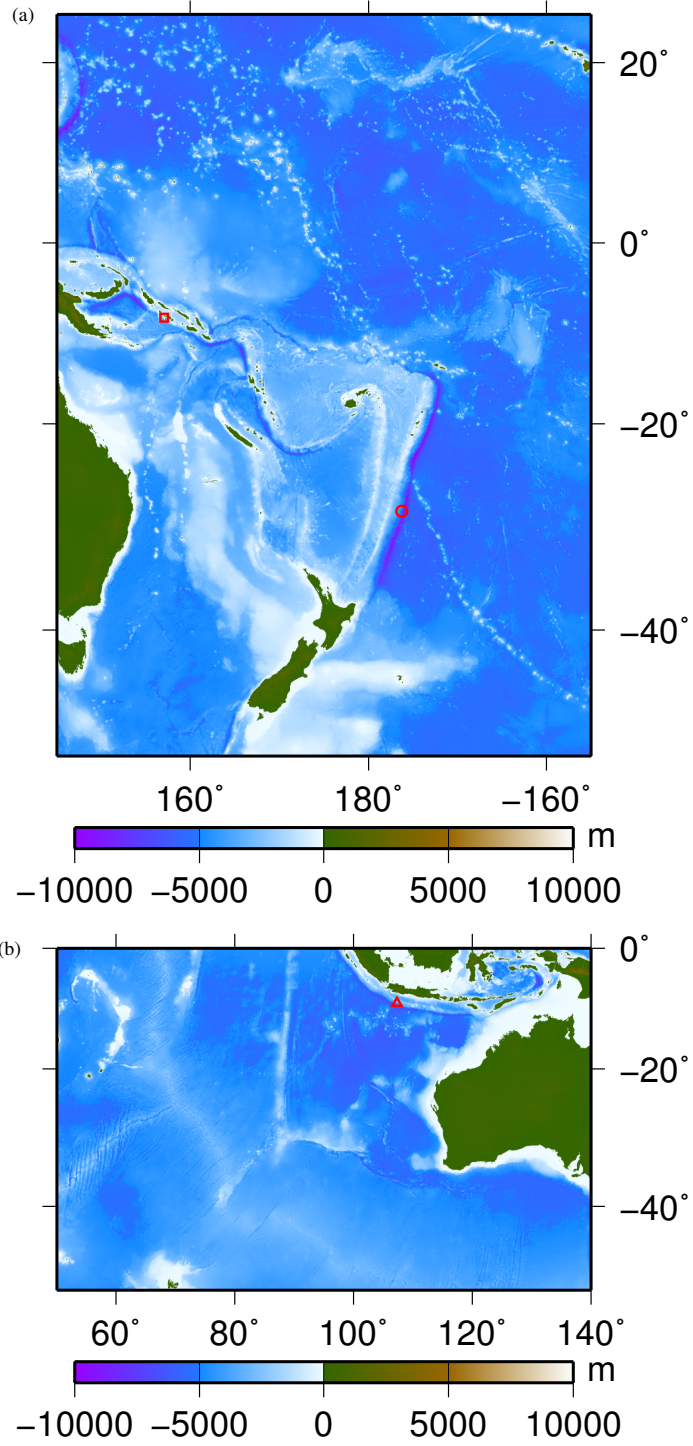

Figure 9. The bathymetry models used for the (a) Kermadec and Solomon Islands scenarios and (b) the Java scenario. The red symbols show the location of the epicentres for each scenario; a circle for the Kermadec scenario, a square for the Solomon Islands scenario and a triangle for the Java scenario.

$M_{\mathrm{w}}=8.5$ for all cases shown. For the last case, where multiple parameters were being varied, the $\sigma$ values were the same as those used in the example discussed in the "Multiple parameters" section. As can be seen, the patterns in this case were broadly similar to the uniform bathymetry case (e.g. Fig. 2b) to the southeast of the epicentre but the nonuniform bathymetry to the northwest of the epicentre greatly increased the complexity of the pattern. Further away from the epicentre, there were patches with a particularly high $\mathrm{CoV}$, such as those to the southeast of New Zealand. These appeared to be in areas of shallow bathymetry or in areas 

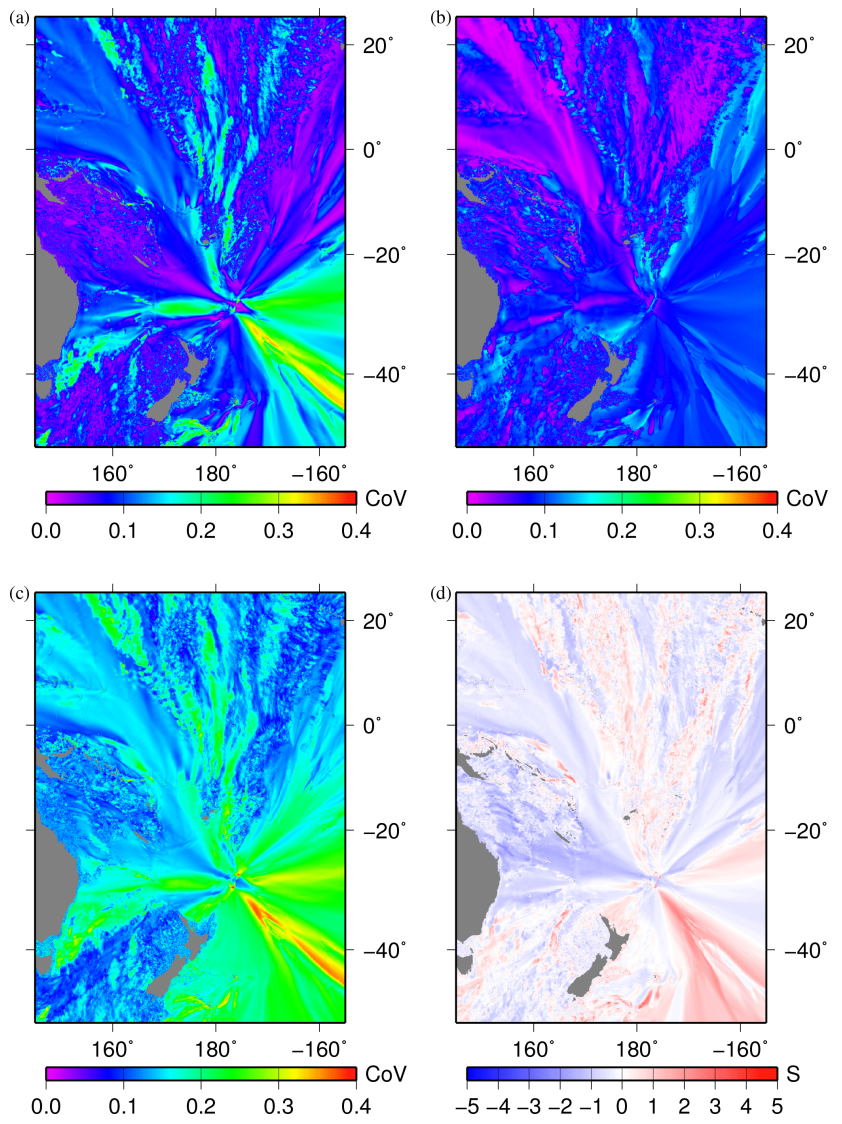

Figure 10. The CoV and skewness maps of $h_{\max }$ from a set of earthquakes on the Kermadec Trench. Each set consisted of $M_{\mathrm{W}}=8.5$ earthquakes where either one parameter was allowed to vary (cases a or b) or all five were allowed to vary (case c). For (a) $\sigma_{\text {strike }}=10^{\circ}$, for (b) $\sigma_{\text {dip }}=5.0^{\circ}$ and for (c) $\sigma_{\text {strike }}=10^{\circ}$, $\sigma_{\text {dip }}=5^{\circ}, \sigma_{\text {rake }}=20^{\circ}$ and $\sigma_{\text {depth }}=2.5 \mathrm{~km}$. (d) The skewness map for case $\mathrm{c}$.

with some shallow bathymetry between them and the source. The CoV in Fig. 10 ranges from 0.5 to 0.04 .

Figure 10 shows the skewness values for the last case (where all parameters allowed to vary). Skewness was generally non-zero and was neither consistently positive nor negative but rather varied across the region.

\subsubsection{Java event}

Figure 11a-c show the CoV maps for an event off Java with the same set of $\sigma$ values used in the previous example. The epicentre of the event was at $107.33^{\circ} \mathrm{E}, 9.32^{\circ} \mathrm{S}$. The mean strike was $295^{\circ}$. Again the broad pattern was similar to that found from the uniform or stepped bathymetry models, but this ceased as soon as any complex bathymetry was reached. For example, the lines of maximum $\mathrm{CoV}$ split as the tsunami went around the southwest corner of Western Australia. The $\mathrm{CoV}$ range for Fig. $11 \mathrm{c}$ was 0.5 to 0.05 .
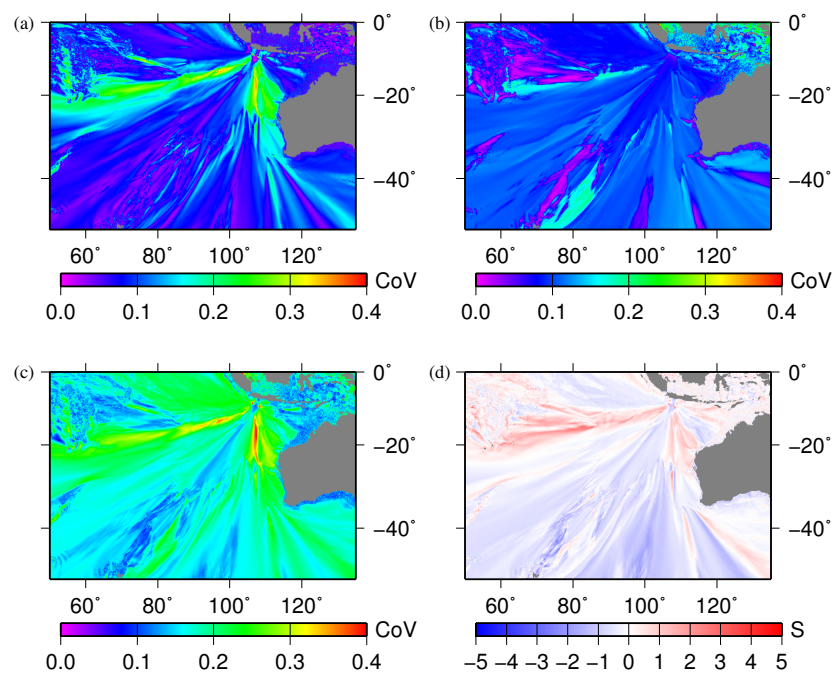

Figure 11. The $\mathrm{CoV}$ and skewness maps of $h_{\max }$ from a set of earthquakes on the Java subduction zone. Each set consisted of $M_{\mathrm{w}}=8.5$ earthquakes where either one parameter was allowed to vary (cases a or b) or all five were allowed to vary (case c). For (a) $\sigma_{\text {strike }}=10^{\circ}$, for (b) $\sigma_{\text {dip }}=5.0^{\circ}$ and for (c) $\sigma_{\text {strike }}=10^{\circ}$, $\sigma_{\text {dip }}=5^{\circ}, \sigma_{\text {rake }}=20^{\circ}$ and $\sigma_{\text {depth }}=2.5 \mathrm{~km}$. (d) The skewness map for case $\mathrm{c}$.

Figure $11 \mathrm{~d}$ shows the skewness pattern for this case. Again the pattern was only similar to the one found with flat bathymetry until the wave reached complex bathymetry.

\subsubsection{Solomon Islands event}

Finally we show an example of the $\mathrm{CoV}$ where the bathymetry is complex in the source region, in this case the Solomon Islands subduction zone (Fig. 12). The epicentre of the event was at $157.06^{\circ} \mathrm{E}, 8.43^{\circ} \mathrm{S}$. The mean strike was $333^{\circ}$. The basic patterns of flat bathymetry examples can now barely be seen, if at all. The highly complex bathymetry in the source made predicting the $\mathrm{CoV}$ pattern at a given location difficult, if not impossible. The skewness map (Fig. 12d) is similarly complex. The highest $\mathrm{CoV}$ and skewness value were, in this case, due north of the earthquake's epicentre. The $\mathrm{CoV}$ ranged from 0.8 to 0.04 (Fig. 12c). The maximum $\mathrm{CoV}$ was significantly higher in this case than for the other two examples, even though the $\sigma$ values for the various parameters were the same. However, the area of extremely high $\mathrm{CoV}$ values were very small.

\section{Discussion}

A few general conclusions can be drawn from these results. Firstly, the exact value of $\mathrm{CoV}$ and the skewness of its distribution was a very strong function of the choice rupture parameter, azimuth, distance and bathymetry. In some cases the reasons for this can be fairly easily understood. For example, consider a set of $M_{\mathrm{w}}=9.5$ earthquakes with varying strike. 

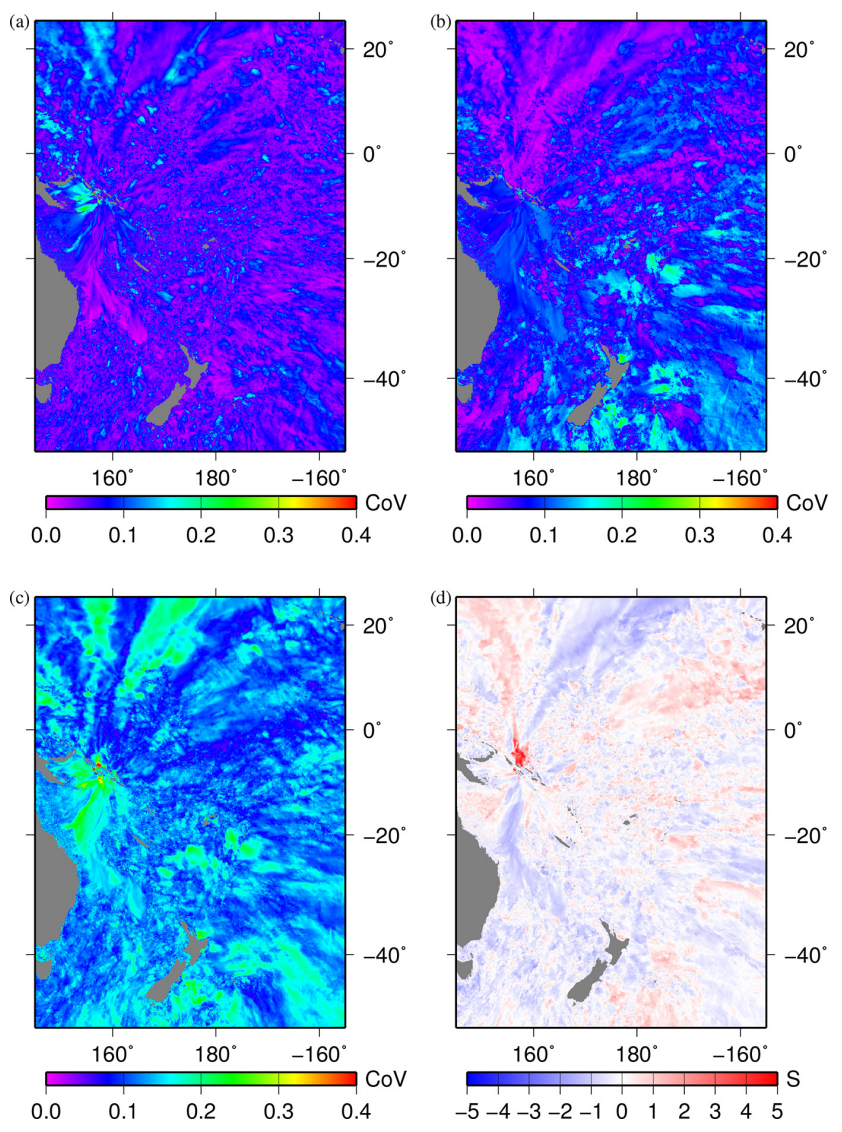

Figure 12. The CoV and skewness maps of $h_{\max }$ from a set of earthquakes on the Solomon Islands subduction zone. Each set consisted of $M_{\mathrm{W}}=8.5$ earthquakes where either one parameter was allowed to vary (cases a or b) or all five were allowed to vary (case c). For (a) $\sigma_{\text {strike }}=10^{\circ}$, for (b) $\sigma_{\text {dip }}=5.0^{\circ}$ and for (c) $\sigma_{\text {strike }}=10^{\circ}$, $\sigma_{\text {dip }}=5^{\circ}, \sigma_{\text {rake }}=20^{\circ}$ and $\sigma_{\text {depth }}=2.5 \mathrm{~km}$. (d) The skewness map for case $\mathrm{c}$.

For points with the beam (i.e. in the main direction of tsunami propagation) any change in strike, positive or negative, will always act to reduce the $h_{\max }$. For points outside the beam any change would reduce $h_{\max }$. Thus the distribution was negatively skewed in the beam and positively skewed outside of it (Fig. 3). The magnitude of this effect will be at its greatest for points just outside the beam since they can go from being entirely inside the beam to entirely outside of it with just a small change in strike. Thus the $\mathrm{CoV}$ was at a maximum there (Fig. 2).

However, the patterns in the other cases are not as intuitive. Having the maximum $\mathrm{CoV}$ along strike when the dip was varied is due to the way the dip changes the initial crustal deformation pattern by bringing the line of displacement closer to the trench. In a similar way, the other changes in $\mathrm{CoV}$ are due to the way changes in other parameters affect the initial deformation pattern.

The fact that the patterns and values change with magnitude suggests strongly that these effects are also linked to the changing dimensions and aspect ratio of the source region. At lower magnitudes ( $M_{\mathrm{w}}=7.5$ in our examples) the source appears to be "point-like" except in the near field. At intermediate magnitudes $\left(M_{\mathrm{W}}=8.5\right.$ in our examples) the source dimensions mean that the source is more "area-like". At large magnitudes ( $M_{\mathrm{w}}=9.5$ in our example) the aspect ratio changes such that the length becomes much greater than the width, and the source becomes "line-like" in the far field.

The reduced sensitivity to uncertainty in depth between $M_{\mathrm{w}}=7.5$ and $M_{\mathrm{w}}=8.5$ can be understood in this context. At $M_{\mathrm{w}}=7.5$ the rupture width was small and therefore occupies a small range of depths, so uncertainty in the depth of the top edge made a significant change to the overall deformation pattern and subsequent tsunami. However at $M_{\mathrm{w}}=8.5$ the larger rupture surface already occupies a wide range of depths, so uncertainty in the depth of the top edge made proportionately less difference overall.

A result of this complexity is that it is very difficult to make general statements about the level of uncertainty in $h_{\max }$ given an uncertainty in any of the source parameters. For some particular locations or azimuths a small uncertainty in strike made very little difference to the result (i.e. less than $10 \%$ ); in other locations it changed $h_{\max }$ by $20 \%$ or even by more than $50 \%$ (Fig. 2). It all depended on the azimuth, and for the latter examples, the bathymetry between the source and the location. This is broadly consistent with Gica et al. (2007) where the same $10^{\circ}$ change in strike could change the wave height measured at Hawaii by between 12 and $84 \%$; depending on the location of the earthquake relative to the island. When the bathymetry in the source location was complex, such as in the Solomon Islands case (Fig. 12), the CoV and skewness maps became impossible to distinguish from noise and only general statements about the maximum upper bound on the CoV or $S$ can really be made.

Initially, the authors assumed that it might be possible to treat the uncertainty in the source parameters as an aleatory, rather than epistemic uncertainty in PTHAs as discussed in the Sect. 1. However, our study shows that including $\sigma$ uncertainties in PTHAs as aleatory uncertainty can only ever be very approximate. It will always be difficult to be sure whether the values used are not over- or underestimating the hazard at a particular location given the highly, and inconsistently, skewed distributions of $h_{\max }$. Since the skew can change from positive to negative over very short length scales these issues cannot be simply solved by using a different type of $\sigma$ (e.g. a $\log$-normal $\sigma$ ). The ideal solution clearly has to be to run a large number of models to try to ensure that the hazard from the events in any tails of these skewed distributions are included in the assessment. However, this can become very computationally challenging for larger assessments.

Similarly, this also means that tsunami databases for tsunami forecasting and warning systems need to be very large. Current warning and forecasting systems still rely on the use of a limited set of precalculated scenarios and do not 
currently include any assessment of the spatial distribution of the $\mathrm{CoV}$ for each scenario, although the $\mathrm{CoV}$ between different scenarios has been calculated (Greenslade et al., 2013). Given the large number of possible events, calculating the $\mathrm{CoV}$ for each event would be an extremely large computational task. It was also noticeable that the CoV distribution for events involving realistic bathymetry tends to become very scattered in shallow coastal areas outside of the near field, possibly the result of complex interference patterns involving multiple waves. This is similar to the scattering in $h_{\max }$ from shallow bathymetric features observed by Mofjeld et al. (2004). Another explanation might be that the resolution of the grids used in our study was not high enough in the coastal regime to properly assess the CoV. In either case, many forecast methodologies rely on warning zones, which are sections of coast in which a warning threshold is crossed once a particular proportion of maximum wave heights (e.g. the 95th percentile) exceeds a specified level (e.g. Uslu and Greenslade, 2013). An area for further study is to see to what extent thresholds defined in these aggregate terms are sensitive to uncertainties in source parameters. If this does effect the reliability of thresholds, it therefore seems advisable to move away from precalculated tsunami databases and use fast tsunami simulation programs instead that allow for the calculation of both the $\mathrm{CoV}$ and $\mu_{\max }$ as the tsunami event unfolds (i.e. ensemble forecasting). The $\mathrm{CoV}$ and the shape of the distribution of $h_{\max }$ from this ensemble of models can then inform about the reliability of the tsunami forecast (and thus the warning) for any given point of interest. It also suggests that warnings should try to move towards taking uncertainties in the source into account more directly in the warning, for example using Bayesian networks (Blaser et al., 2011, 2012).

In addition to the potential issues just discussed, our results also indicate that the inversion of the tsunami source based on DART ${ }^{\circledR}$ buoy information will be affected by the relative positions of the source and the DART ${ }^{\circledR}$ buoys. If a DART $^{\circledR}$ buoy happens to be located in an area that has a low $\mathrm{CoV}$ for a particular fault parameter, we would expect the resulting inversion for that parameter to be poorly constrained. In other words, the inverted source is non-unique. For example, if the inversion only has DART ${ }^{\circledR}$ buoys close to a $M_{\mathrm{w}}=9.5$ earthquake, the maximum wave height at those DART $^{\circledR}$ buoys will not be significantly affected by an error in strike unless one of them happens to be close to the edge of the rupture (see Fig. 2c-d). Thus the strike may not be wellconstrained. However, the same error in strike could make a large difference in the observed maximum wave height further from the source (i.e. in the red areas in Fig. 2c-d). This is consistent with the observation of Wang (2008) that gauges off the centre line of the tsunami propagation are more useful for constraining the source than those in tsunami beam itself. Ultimately, this sort of effect will create more uncertainty in the predicted wave fields. Reducing the uncertainty ideally requires techniques which can measure the tsunami wave height over broad areas (e.g. using remote sensing) or include additional types of data (e.g. seismic or geodetic). Also many inversion algorithms assume a Gaussian or lognormal distribution of misfits; as can be seen from the maps of skewness, this is not always the case. The effect of this on tsunami inversion assumptions is also be another potential area of future research.

\section{Conclusions}

The main conclusion of this study is that "the uncertainty in the maximum wave height of a tsunami is a complex function of our uncertainty in the source parameters and bathymetry". Even for the case of a completely flat bathymetry, complex patterns of $\mathrm{CoV}$ and skewness were seen. These patterns became even more complex when realistic bathymetries were used. While the specifics of these $\mathrm{CoV}$ maps may be influenced by the particular choice of numerical and bathymetry models used here, the overall patterns are probably not. For example, the high CoV lobes to each side of the beam when the strike was varied appear to be a function of the beam-like nature of tsunami propagation. Thus any model or bathymetry is likely to have a broadly similar CoV map even if the details may be different.

Given the complexity of $\mathrm{CoV}$ (and thus $\sigma$ ), simplified methods of taking earthquake uncertainty into account in PTHAs have the potential to be quite inaccurate. Depending on the way $\sigma$ or $\mathrm{CoV}$ is chosen, they will overestimate the hazard in some locations and underestimate it in others. Also, $\sigma$ does not follow a simple-normal or log-normal distribution as shown by the fact that the skewness also changes with distance and azimuth. This suggest that the best way to incorporate uncertainty in earthquake parameters in future PTHAs is still to model all reasonably possible earthquake ruptures. Similarly, these results give further impetus towards using real-time ensemble tsunami propagation models for warnings, rather than relying on limited catalogues of possible future tsunamis. The already substantial computational task of both activities will thus likely need to grow even further in future in order to take uncertainties such as these into account.

Author contributions. D. Burbidge ran the models, wrote the scripts for analysing the results, prepared the figures, wrote the bulk of the text and the response to reviewers. C. Mueller wrote the Python API which managed the simulations. Both C. Mueller and W. Power contributed text to the final version of the manuscript, mostly to the Introduction, Method and Discussion sections.

Acknowledgements. The authors would like to thank A. Babeyko for assisting the authors with the EasyWave tsunami propagation model. All the figures in this paper were created using GMT (Wessel et al., 2013). Finally, the authors would also like to thank 
the three anonymous referees and X. Wang, N. Horspool and J. Sexton for reviewing this document. The paper is published with the permission of the CEO of Geoscience Australia.

Edited by: I. Didenkulova

Reviewed by: three anonymous referees

\section{References}

Abe, K.: Reliable estimation of the seismic moment of large earthquakes, J. Phys. Earth, 23, 381-390, 1975.

Babeyko, A.: EasyWave: fast tsunami simulation tool for early warning, http://trac.gfzpotsdam.de/easywave (last access: 13 May 2015), 2012.

Blaser, L., Ohrnberger, L. M., Riggelsen, C., Babeyko, A., and Scherbaum, F.: Bayesian networks for tsunami early warning, Geophys. J. Int., 185, 1431-1443, 2011.

Blaser, L., Ohrnberger, M., Krüger, F., and Scherbaum, F.: Probabilistic tsunami threat assessment of 10 recent earthquakes offshore Sumatra, Geophys. J. Int., 188, 1273-1284, 2012.

Burbidge, D., Mleczko, R., Thomas, C., Cummins, P., Nielsen, O., and Dhu, T.: A Probabilistic Tsunami Hazard Assessment for Australia, Geoscience Australia Professional Opinion 2008/04, Canberra, Australia, 2008.

Burbidge, D., Cummins, P. R., Mleczko, R., and Thio, H. K.: A probabilistic tsunami hazard assessment for Western Australia, Pure Appl. Geophys., 165, 2059-2088, 2009.

Charette, M. A. and Smith, W. H. F.: The Volume of Earth's Ocean, Oceanography, 23, 112-114, 2010.

Dao, M. H. and Tkalich, P.: Tsunami propagation modelling a sensitivity study, Nat. Hazards Earth Syst. Sci., 7, 741-754, doi:10.5194/nhess-7-741-2007, 2007.

Davies, G., Horspool, N., and Miller, V.: Tsunami inundation from real heterogeneous earthquake slip distributions: Evaluations of synthetic source models, J. Geophys. Res.-Solid Ea., 120, doi:10.1002/2015JB012272, in press, 2015.

Geist, E. L.: Local tsunamis and earthquake source parameters, Adv. Geophys., 39, 117-209, 1999.

Geist, E. L.: Complex earthquake rupture and local tsunamis, J. Geophys. Res.-Solid Ea., 107, 2-1-2-15, doi:10.1029/2000JB000139, 2002.

Geist, E. L.: Phenomenology of tsunamis: Statistical properties from generation to runup, Adv. Geophys., 51, 107-169, doi:10.1016/S0065-2687(09)05108-5, 2009.

Geist, E. L.: Phenomenology of tsunamis II: Scaling, Event Statistics, and Inter-Event Trigeering, Adv. Geophys., 53, 35-92, doi:10.1016/B978-0-12-380938-4.00002-1, 2012.

Geist, E. L. and Parsons, T.: Probabilistic Analysis of Tsunami Hazards, Nat. Hazards, 37, 277-314, doi:10.1007/s11069-005-4646z, 2006.

Gica, E., Teng, M. H., Liu, P. L.-F., Titov, V., and Zhou, H.: Sensitivity Analysis of Source Parameters for Earthquake-Generated Distant Tsunamis, J. Waterway Port Coast. Ocean Eng., 133, 429-441, 2007.

Glimsdal, S., Pedersen, G. K., Harbitz, C. B., and Løvholt, F.: Dispersion of tsunamis: does it really matter?, Nat. Hazards Earth Syst. Sci., 13, 1507-1526, doi:10.5194/nhess-13-15072013, 2013.
Goda, K., Mai, P. M., Yasuda, T., and Mori, N.: Sensitivity of tsunami wave profiles and inundation simulations to earthquake slip and fault geometry for the 2011 Tohoku earthquake, Earth Planets Space, 66, 1-20, doi:10.1186/1880-5981-66-105, 2014.

Goda, K., Yasuda, T., Mori, N., and Mai, P. M.: Variability of tsunami inundation footprints considering stochastic scenarios based on a single rupture model: Application to the 2011 Tohoku earthquake, J. Geophys. Res.-Oceans, 120, 4552-4575, doi:10.1002/2014JC010626, 2015.

González, F., Geist, E., Jaffe, B., Kânoglu, U., Mofjeld, H., Synolakis, C., Titov, V., Arcas, D., Bellomo, D., Carlton, D., Horning, T., Johnson, J., Newman, J., Parsons, T., Peters, R., Peterson, C., Priest, G., Venturato, A., Weber, J., Wong, F., and Yalciner, A.: Probabilistic tsunami hazard assessment at Seaside, Oregon for near- and far-field seismic sources, J. Geophys. Res., 114, C11023, doi:10.1029/2008JC005132, 2009.

Greenslade, D. J. M., Simanjuntak, M. A., Burbidge, D., and Chittleborough, J.: A first-generation real-time tsunami forecasting system for the Australian region, BMRC Research Report 126, Bureau of Meteorology, Melbourne, Australia, 2007.

Greenslade, D. J. M., Annunziato, A., Babeyko, A., Burbidge, D., Ellguth, E., Horspool, N., Srinivasa Kumar, T., Kumar, C. P., Moore, C., Rakowsky, N., Riedlinger, T., Ruangrassamee, A., Srivihok, P., and Titov, V. V.: An Assessment of the Diversity in Scenario-based Tsunami Forecasts for the Indian Ocean, Cont Shelf Res., 79, 36-45, 2013.

Hanks, T. C. and Bakun, W. H.: A bilinear source-scaling model for M-log A observations of continental earthquakes, Bull. Seismol. Soc. Am., 95, 1841-1846, 2002.

Hayes, G. P., Wald, D. J., and Johnson, R. L.: Slab1.0: A threedimensional model of global subduction zone geometries, J. Geophys. Res., 117, B01302, doi:10.1029/2011JB008524, 2012.

Heidarzadeh, M. and Kijko, A.: A probabilistic tsunami hazard assessment for the Makran subduction zone at the northwestern Indian Ocean, Nat. Hazards, 56, 577-593, doi:10.1007/s11069010-9574-x, 2011.

Horspool, N., Pranantyo, I., Griffin, J., Latief, H., Natawidjaja, D. H., Kongko, W., Cipta, A., Bustaman, B., Anugrah, S. D., and Thio, H. K.: A probabilistic tsunami hazard assessment for Indonesia, Nat. Hazards Earth Syst. Sci., 14, 3105-3122, doi:10.5194/nhess-14-3105-2014, 2014.

Kagan, Y. Y.: Accuracy of modern global earthquake catalogs, Phys. Earth Planet. Int., 135, 173-209, 2003.

Kaiser, G., Scheele, L., Kortenhaus, A., Lovholt, F., Romer, H., and Lesdchka, S.: The influence of land cover roughness on the results of high resolution tsunami inundation modeling, Nat. Hazards Earth Syst. Sci., 1, 2521-2540, doi:10.5194/nhess-11-25212011, 2011.

Lorito, S., Selva, J., Romano, F., Tiberti, M. M., and Piatanesi, A.: Probabilistic hazard for seismically induced tsunamis: accuracy and feasibility of inundation maps, Geophys. J. Int., 200, 574 588, doi:10.1093/gji/ggu408, 2015.

Løvholt, F., Pedersen, G., Bazin, S., Kuhn, D., Bredesen, R. E., and Harbitz, C.: Stochastic analysis of tsunami runup due to heterogeneous coseismic slip and dispersion, J. Geophys. Res., 117, C03047, doi:10.1029/2011JC007616, 2012.

Løvholt, F., Glimsdal, S., Smebye, H., Griffin, J., and Davis, G.: UN-ISDAR Global Assessment Report 2015, Tsunami methodology and result overview, Report Number 20120052-03-R, 
United Nations Office for Disaster Risk Reduction, Geneva, Switzerland, 2014.

Mantalos, P.: Three Different Measures of Sample Skewness and Kurtosis and their Effects on the Jarque-Bera Test for Normality, Jönköping International Business School Working Papers No. 2010-9, Jönköping University, Jönköping, Sweden, 2010.

Marzocchi, W. and Jordan, T. H.: Testing for ontological errors in probabilistic forecasting models of natural systems, P. Natl. Acad. Sci. USA, 111, 11973-11978, doi:10.1073/pnas.1410183111, 2014.

McCloskey, J., Antonioli, A., Piatanesi, A., Sieh, K., Steacy, S., Nalbant, S. S., Cocco, M., Giunchi, C., Huang, J. D., and Dunlop, P.: Near-field propagation of tsunamis from megathrust earthquakes, Geophys. Res. Lett., 34, L14316, doi:10.1029/2007GL030494, 2007.

McCloskey, J., Antonioli, A., Piatanesi, A., Sieh, K., Steacy, S., Nalbant, S., Cocco, M., Giunchi, C., Huang, J., and Dunlop, P.: Tsunami Threat in the Indian Ocean from a Future Megathrust Earthquake West of Sumatra, Earth Planet. Sc. Lett., 265, 61-81, 2008.

Mofjeld, H. O., Symons, C. M., Lonsdale, P., Gonzalex, F. I., and Titov, V. V.: Tsunami scattering and earthquake faults in the deep Pacific Ocean, Oceanography, 17, 38-46, 2004.

Myers, E. P. and Baptista, A. M.: Analysis of Factors Influencing Simulations of the 1993 Hokkaido Nansei-Oki and 1964 Alaska Tsunamis, Nat. Hazards, 23, 1-28, 2001.

NOAA: 2-minute Gridded Global Relief Data (ETOPO2v2), US Department of Commerce, National Oceanic and Atmospheric Administration, National Geophysical Data Center, http://www.ngdc.noaa.gov/mgg/fliers/06mgg01.html (last access: 8 October 2009), 2006.

Okal, E. A. and Synolakis, C. E.: Source discriminants for near-field tsunamis, Geophys. J. Int., 158, 899-912, 2004.

Okal, E. A. and Synolakis, C. E.: Far-field tsunami hazard from mega-thrust earthquakes in the Indian Ocean, Geophys. J. Int., 172, 995-1015, 2008.

Power, W.: Review of Tsunami Hazard in New Zealand (2013 Update), GNS Science Consultancy Report 2013/131, GNS Science, Lower Hutt, New Zealand, p. 222, 2013.

Power, W., Downes, G., and Stirling, M.: Estimation of Tsunami Hazard in New Zealand due to South American Earthquakes, Pure Appl. Geophys., 164, 547-564, doi:10.1007/s00024-0060166-3, 2007.
Scholz, C. H.: Scaling laws for large earthquakes: consequences for physical models, Bull. Seismol. Soc. Am., 72, 1-14, 1982.

Shaw, B. and Jackson, J.: Earthquake mechanisms and active tectonics of the Hellenic subduction zone, Geophys. J. Int., 181, 966-984, 2010.

Shuto, N.: Numerical simulation of tsunamis? Its present and near future, Nat. Hazards, 4, 171-191, doi:10.1007/BF00162786, 1991.

Sørensen, M. B., Spada, M., Babeyko, A., Wiemer, S., and Grünthal, G.: Probabilistic tsunami hazard in the Mediterranean Sea, J. Geophys. Res., 117, B01305, doi:10.1029/2010JB008169, 2012.

Thio, H. K., Somervile, P., and Polet, J.: Probabilistic Tsunami Hazard in California, Pacific Earthquake Engineering Research Center Report 2010/108, Pacific Earthquake Engineering Center, University of California, Berkeley, California, USA, 2010.

Titov, V. V., Mofjeld, H. O., Gonzalez, F. I., and Newman, J. C.: Offshore forecasting of Alaska-Aleutian Subduction Zone tsunamis in Hawaii, NOAA Technical Memorandum ERL PMEL-114, NOAA, Seattle, 1999.

Uslu, B. and Greenslade, D. J. M.: Validation of Tsunami Warning Thresholds Using Inundation Modelling, CACWR Technical Report No. 062, The Centre for Australian Weather and Climate Research, Melbourne, Australia, 2013.

Wang, X.: Numerical modelling of surface and internal waves over shallow and intermediate water, $\mathrm{PhD}$ thesis, Cornell University, Ithaca, New York, 2008.

Weisz, R. and Winter, C.: Tsunami, tides and run-up: a numerical study, in: Proceedings of the International Tsunami Symposium, 27-29 June 2005, edited by: Papadopoulos, G. and Satake, K., Chania, Greece, p. 322, 2005.

Wessel, P., Smith, W. H. F., Scharroo, R., Luis, J., and Wobbe, F.: Generic Mapping Tools: Improved Version Released, EOS Trans. AGU, 94, 409-410, doi:10.1002/2013EO450001, 2013.

Xing, H. L., Ding, R. W., and Yuen, D. A.: Tsunami Hazards along the Eastern Australian Coast from Potential Earthquakes: Results from Numerical Models, Pure Appl. Geophys., 172, 2087-2115, doi:10.1007/s00024-014-0904-x, 2015. 